\title{
Stability criteria for flooded vehicles: a state-of-the-art review
}

\author{
E. Martínez-Gomariz ${ }^{1}$, M. Gómez ${ }^{1}$, B. Russo² and S. Djordjevic ${ }^{3}$ \\ 1 FLUMEN Research Institute, Technical University of Catalonia, Barcelona, Spain \\ 2 Group of Hydraulic and Environmental Engineering, Technical College of La Almunia (EUPLA), University of Zaragoza, Zaragoza, Spain \\ 3 Centre for Water Systems, University of Exeter, Exeter, UK
}

\section{Correspondence \\ Eduardo Martínez-Gomariz, FLUMEN \\ Research Institute, Technical University of \\ Catalonia, Barcelona, Spain. \\ Email: eduardo.martinez-gomariz@upc.edu}

DOI: $10.1111 / \mathrm{jfr} 3.12262$

Key words

Drainage system; hazard; risk; urban flood; vehicles stability.

\begin{abstract}
Hazard conditions related to vehicular circulation are important in flood risk management. The knowledge of vehicles stability when those are exposed to flooding is crucial for an informed flood risk management in urban areas. After losing stability, the vehicle becomes buoyant and may be washed away with potential injuries and fatalities. Therefore, the analysis of the stability of vehicles exposed to flooding is important in order to make decisions to reduce the damages and hazards. Herein a comprehensive state-of-the-art on stability of vehicles exposed to flooding is presented. The different studies have been gathered in experimental, theoretical and guidelines proposals and all of them focusing on parked vehicles. There is a clear need to conduct more research in this field by testing a greater variety of models in order to offer a more general methodology to define stability threshold for any vehicle exposed to flooding. Nevertheless, in this work, it has been demonstrate that the most safety stability criterion for vehicles exposed to flooding up to now is the proposed in the Guide AR\&R.
\end{abstract}

\section{Introduction}

After a rainfall event, only a part of the runoff is captured by the inlets, while any exceedance flow may continue over the street. An inadequate inlet spacing or insufficient capacity of the underground sewer system, combined with an increase of urbanised areas all over the world, may lead to high amounts of water on streets. In this sense, the design of drainage systems should consider the dual drainage concept (Djordjevic et al., 1999; Schmitt et al., 2004; Nasello and Tucciarelli, 2005; Concha and Gómez, 2009; Nanía et al., 2015), through which certain amount of runoff is assumed to flow on the streets because only a portion of runoff can be conveyed by the sewer system. Therefore, after a sewer network is designed, an important question should be answered: what are the consequences, in terms of flood hazard, of the water running off the streets?

The hazard produced by surface water, as many authors propose in literature, is related to a combination of the hydraulic variables - water depth and velocity. That is to say that the hazard must be understood as a part of the risk, together with the vulnerability, which may be assessed from the 'easy' to calculate water depth and velocity (Sanyal and Lu, 2006; Russo et al., 2013b; Van Drie et al., 2013). These hydraulic variables will determine the hazard level which might affect pedestrians, vehicles and properties.

The numbers of vehicles in our cities appears to be ascending. Thus, it is essential to analyse the hazard regarding vehicles exposed to flooding in urban areas. The hazard study for vehicles exposed to water flows has to be based on the determination of their stability threshold. There are three typical modes of vehicle instability: floating, sliding and toppling (Shand et al., 2011); however, the most frequent are the first two and for the most of cases the instability occurs as a combination of both, floating and sliding. On the one hand, vehicle stability analysis is simpler than pedestrian stability studies because manoeuvrability, abilities and psychological aspects do not need to be taken into account, but on the other hand the integrity of the vehicle occupants may be compromised (i.e. intangible damages).

The vehicles instability in case of floods can generate tangible direct damages due to the physical contact of water with them, but also indirect tangible damages (like loss of production) due to traffic disruption. Moreover, after losing stability, the vehicle becomes buoyant and may be washed away colliding with urban elements with potential injuries or fatalities (intangible damage). In this way, vehicles might be considered as massive debris washed away by the flood 
that could generate significant economic damages and compromising pedestrian safety. A clear illustration of these damages is the massive flash flood that occurred in Boscastle (UK) on 16 August 2004 caused by an extreme rainfall event up to $200 \mathrm{~mm}$ in $5 \mathrm{~h}$, causing millions of pounds of damages and more than 100 vehicles washed away. Furthermore, the washed out vehicles caused the blockage of a bridge, which collapsed, aggravating notably the damages. These kinds of events are not uncommon, with greater or lesser consequences, and Spanish urban areas as well were struck by massive flash floods recently. The city of Santa Cruz de Tenerife (Spain) on 19 October 2014 was struck by a flood caused by an up to $139.2 \mathrm{~mm}$ and $15 \mathrm{~h}$ duration rainfall (Figure 1), being the highest recorded precipitation in the last 70 years. The consequences of this event were tangible and intangible damages: loss of energy supply for more than 4000 users, lots of vehicles flooded and washed away, massive material damages in properties and urban elements, two injured pedestrians and one death. The death was the result of a heart attack after a woman was washed away by the water flow and became trapped under a parked vehicle.

Vehicles stability will be compromised when the hydraulic variables [i.e. flow depth $(y)$ and velocity (v)] exceed a certain threshold, similar to the stability threshold of pedestrians exposed to water flows (Abt et al., 1989; Russo et al., 2013a; Xia et al., 2014; Xia et al., 2016; Martínez-Gomariz et al., 2016; Cox, 2010). However, in the case of vehicles, their characteristics (e.g. weight, shape and design) will determine the level of stability. Car design has evolved over the years and today it is possible to find an endless variety of dimensions and designs. Thus, some of them have a hydrodynamic behaviour that may improve the stability, but probably in contrast those present smaller ground clearance that reduces the stability when they are flooded.

In this paper, a comprehensive state-of-the-art on stability of vehicles exposed to flooding is presented. The research on stability of vehicles in flooding may be classified into experimental or theoretical studies and the proposals for guidelines regarding vehicle stability. The latter are recommendations or guidelines in different countries that are rarely based on any experimental or theoretical work or otherwise the source of the proposed criterion is not provided. Most identified studies were focused on parked vehicles, possibly due to the great complexity of the stability analysis of vehicles in motion. Finally, some conclusions are presented regarding the most appropriate criterion proposed up to now and future research.

\section{Experimental and theoretical studies}

The earliest study was carried out by Bonham and Hattersley (1967) and consisted of stability analysis of a small-scale (1:25) Ford Falcon model exposed to perpendicular flow (relative to the vehicle length). The tested model was restrained by vertical and lateral threads through which forces were measured. Tests were carried out at 46 combinations of water depths ranging from 0.11 to $0.57 \mathrm{~m}$ and velocities from 0.48 to $3.09 \mathrm{~m} / \mathrm{s}$ (prototype values). Loss of stability due to buoyancy was found to occur at a depth of $0.57 \mathrm{~m}$. The obtained vertical and horizontal forces were used to calculate the friction coefficients between tyre and ground and identify lines of constant friction (in the representation of depth and velocity combinations for each instability situation) produced for friction coefficient between 0.3 and 0.5 . Finally, the lower threshold of the constant friction coefficient of 0.3 was proposed as an adequate limit function. Through principles of geometric similarity, results were used to determine limits of floating and frictional stability for a range of vehicles available at the time. The buoyancy depths ranged from 0.38 to $0.58 \mathrm{~m}$.

Gordon and Stone (1973) carried out experimental tests, studying the instability of a small-scale (1:16) model Morris Mini sedan exposed to parallel flow (i.e. relative to the vehicle length) in a $1 \mathrm{~m}$ wide flume. This vehicle was selected as representative at that time, considering it was the most susceptible to losing stability in flooding. Three modes of resistance to movement were considered (i.e. front wheels locked, rear wheels locked and all wheels locked) and as well total horizontal and vertical reaction forces were measured through fine threads in the same way as in Bonham and Hattersley (1967). Lines of constant friction coefficient (between 0.3 and 1.0) to initiate vehicle movement as a function of depth and velocity were derived for the locked front wheel condition and for the locked rear condition.

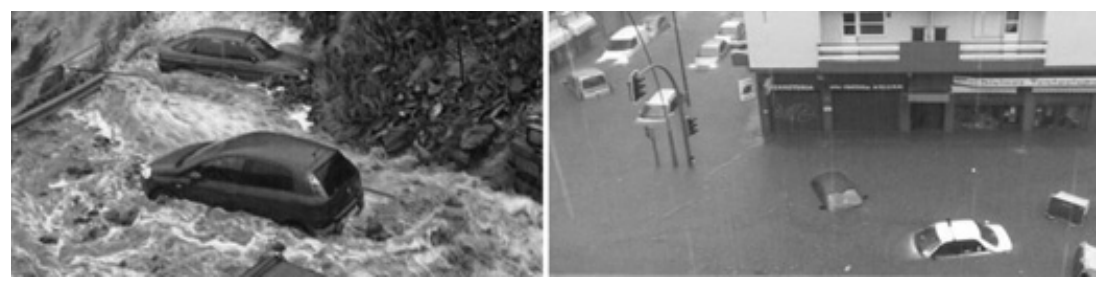

Figure 1 Flooded vehicles in the 2014 Tenerife (Spain) flood. 
Keller and Mitsch (1993) undertook a theoretical study of the stability of both cars and people. Regarding vehicles, it was considered that vehicle instability occurred when the vertical reaction force is less than or equal to zero (vehicle floats) or when the horizontal force is equal to the vertical restoring force which is a function of the assumed friction coefficient and the vertical reaction force (vehicle slides). Flow depths ranged from 0.025 up to 0.4 , which determined the submerged area projected normally to the flow and the water drag force (i.e. the horizontal force) was defined. Four types of cars were considered, Suzuki Swift, Ford Laser, Toyota Corolla and Ford LTD, proposing a theoretical limit of stability as a function of depth and velocity, for each one. However, the definition of these functions was dependent on the selection of friction and drag coefficients. In this study a friction coefficient of 0.3 , following Gordon and Stone (1973) suggestion, and drag coefficient values of 1.1 (on the wheels) and 1.15 (on the vehicle body) were adopted.

The research on the stability of vehicles involved in flooded was taken up by Teo (2010) and Teo et al. (2012, 2013) in the laboratory of the Cardiff School of Engineering (UK). Experimental tests were carried out based on smallscale (1:43) vehicles models; Mitsubishi Pajero, BMW M5 and Mini Cooper. The tests were undertaken in two different horizontal flumes (of width $0.3 \mathrm{~m}$ and $1.2 \mathrm{~m}$ ), in order to consider the influence of flume walls on the results. A comprehensive study of several oncoming flow orientations with respect to the vehicle length was carried out in order to determine lower values of water depth and velocity that can lead to vehicle instability. It was concluded that the most influential oncoming flow orientation was perpendicular respect to the vehicle length, as expected. Moreover, four tests with 1:18 scaled models were undertaken in order to validate the results of 1:43 scaled models. Linear depthvelocity relationships were established as stability thresholds for prototypes, distinguishing two clear tendencies for each vehicle: one for water depths higher than the vehicle height and the other one for water depths lower than the vehicle height. Finally, after overlapping the threshold functions, three zones were proposed: stable zone, transition zone (i.e. zone occupied for the three overlapped threshold functions) and unstable zone.

Nevertheless, although it was stated that Froude similarity had been ensured, the fact is that the weight of the scaled models was not modified according to the Froude similarity. In this sense, three conclusions might be reached: (1) the validation of the 1:43 scaled models results

Table 1 Summary of theoretical and analytical studies [adapted from Shand et al. (2011)] (1 of 2)

\begin{tabular}{|c|c|c|c|c|}
\hline Reference & $\begin{array}{c}\text { Bonham and } \\
\text { Hattersley (1967) }\end{array}$ & $\begin{array}{l}\text { Gordon and } \\
\text { Stone (1973) }\end{array}$ & Keller and Mitsch (1993) & Teo (2010) \\
\hline $\begin{array}{l}\text { Study type } \\
\text { Vehicles tested }\end{array}$ & $\begin{array}{c}\text { Experimental } \\
\text { - Ford Falcon } \\
\text { - Results scaled to } \\
\text { other models }\end{array}$ & $\begin{array}{l}\text { Experimental } \\
\text { Morris Mini } \\
\text { Sedan }\end{array}$ & $\begin{array}{l}\text { Theoretical } \\
\text { - Toyota Corolla } \\
\text { - Suzuki Swift } \\
\text { - Ford Laser } \\
\text { - Honda Civic } \\
\text { - Ford LTD }\end{array}$ & $\begin{array}{l}\text { Experimental } \\
\text { - MINI Cooper } \\
\text { - BMW M5 } \\
\text { - Mitsubishi Pajero }\end{array}$ \\
\hline Vehicle age & Mid to late 1960 s & Early 1970 s & Early 1990 s & Actuals \\
\hline Ground clearance $(\mathrm{m})$ & 0.18 & 0.15 & $0.155 ; 0.17 ; 0.15 ; 0.10 ; 0.16$ & $0.149 ; 0.117 ; 0.225$ \\
\hline Scale & $1: 25$ & $1: 16$ & - & $1: 43$ y $1: 18$ \\
\hline Vehicle orientation & $\begin{array}{l}\text { Vehicle } \\
\text { perpendicular } \\
\text { to flow }\end{array}$ & $\begin{array}{l}\text { Vehicle } \\
\text { parallel } \\
\text { to flow }\end{array}$ & Vehicle perpendicular to flow & $\begin{array}{c}\text { Vehicle parallel firstly. Orientation } \\
\text { effects study. Vehicle } \\
\text { perpendicular lastly }\end{array}$ \\
\hline $\begin{array}{l}\text { Range of depths tested } \\
\text { (m) (prototype) }\end{array}$ & $0.11-0.57$ & $0.12-0.57$ & $0.025-0.375$ & $0.645-4.816$ \\
\hline $\begin{array}{l}\text { Range of velocities } \\
\text { tested }(\mathrm{m} / \mathrm{s}) \\
\text { (prototype) }\end{array}$ & $0.48-3.09$ & $0.5-3.69$ & $0.6->3.5$ & $2.37-7.94$ \\
\hline $\begin{array}{l}\text { Buoyancy depth } \\
\text { (m) (prototype) }\end{array}$ & 0.57 & $\begin{array}{c}0.42 \text { (rear) and } \\
0.5 \text { (front) }\end{array}$ & Between 0.34 and 0.4 for different & Not available \\
\hline \multirow[t]{2}{*}{$\begin{array}{l}\text { Resultant equation of } \\
\text { stability }\end{array}$} & $\frac{F_{\mathrm{H}}}{\mu F_{\mathrm{V}}}=1$ & $\frac{F_{\mathrm{H}}}{\mu F_{\mathrm{V}}}=1$ & $U_{\mathrm{c}}=2 \cdot\left(\frac{\mu F_{\mathrm{v}}}{\rho_{\mathrm{w}} C_{\mathrm{d}} \mathrm{A}}\right)^{1 / 2}$ & $U_{\mathrm{c}}=2 \cdot\left(\frac{\mu \mathrm{FV}_{\mathrm{v}}}{\rho_{\mathrm{w}} \mathrm{C}_{\mathrm{d}} \mathrm{A}}\right)^{1 / 2}$ \\
\hline & & & $\begin{array}{l}\text { Note: } F_{\mathrm{v}} \text { and therefore } U_{\mathrm{c}} \text { are } \\
\text { evaluated separately for the } \\
\text { front and rear axle. }\end{array}$ & $\begin{array}{c}\text { Note: Both axles were blocked. } \\
\text { Friction is divided between four } \\
\text { wheels. }\end{array}$ \\
\hline $\begin{array}{l}\text { Assumed coefficient of } \\
\text { friction }\end{array}$ & $\begin{array}{r}\text { Various, although } \\
\text { recommends } 0.3\end{array}$ & Various & 0.3 & - \\
\hline
\end{tabular}


Table 2 Summary of theoretical and analytical studies [adapted from Shand et al. (2011)] (2 of 2)

\begin{tabular}{|c|c|c|c|c|}
\hline References & Xia et al. (2010) & Shu et al. (2011) & $\begin{array}{l}\text { Toda } \\
\text { et al. (2013) }\end{array}$ & Xia et al. (2013) \\
\hline $\begin{array}{l}\text { Study type } \\
\text { Vehicles tested }\end{array}$ & $\begin{array}{l}\text { Theoretical } \\
\text { Validation of his derived } \\
\text { formula based on Teo } \\
\text { (2010) experimental results }\end{array}$ & $\begin{array}{l}\text { Experimental and theoretical } \\
* \text { Ford Focus } \\
* \text { Ford transit } \\
* \text { Volvo Xc90 }\end{array}$ & $\begin{array}{l}\text { Experimental } \\
* \text { Tipo Sedan } \\
* \text { Tipo } \\
\quad \text { Minivan }\end{array}$ & $\begin{array}{l}\text { Experimental and theoretical } \\
\text { * Honda Accord } \\
\text { *Audi Q7 }\end{array}$ \\
\hline Vehicle age & Actuals & Actuals & Actuals & Actuals \\
\hline $\begin{array}{l}\text { Ground } \\
\quad \text { clearance }(m)\end{array}$ & $0.149 ; 0.117 ; 0.225$ & $0.101 ; 0.166 ; 0.218$ & - & $0.155 ; 0.206$ \\
\hline Scale & - & $1: 18$ & $\begin{array}{l}\text { 1:10 (Sedan) } \\
\text { 1:18 } \\
\quad \text { (Minivan) }\end{array}$ & $1: 14$ \\
\hline Vehicle orientation & Vehicle parallel to flow & Vehicle parallel to flow & $\begin{array}{l}\text { Vehicle } \\
\text { parallel } \\
\text { to flow }\end{array}$ & $\begin{array}{l}\text { Vehicle parallel and } \\
\text { perpendicular to flow }\end{array}$ \\
\hline $\begin{array}{l}\text { Range of depths } \\
\text { tested } \\
\text { (m) (prototype) }\end{array}$ & $0.3-3.0$ & $0.16-0.62$ & $0.28-0.72$ & $0.11-0.65$ \\
\hline $\begin{array}{l}\text { Range of velocities } \\
\text { tested (m/s) } \\
\text { (prototype) }\end{array}$ & $4.0-0.5$ & $0.18-6.24$ & $0.71-5.68$ & $0.55-8.93$ \\
\hline $\begin{array}{l}\text { Buoyancy depth } \\
\text { (m) (prototype) }\end{array}$ & Not available & Not Available & $\begin{array}{l}\text { Buoyancy } \\
\text { variable }\end{array}$ & $\begin{array}{l}0.45 \text { (Honda) } \\
0.67 \text { (Audi) }\end{array}$ \\
\hline $\begin{array}{l}\text { Resultant equation } \\
\text { of stability }\end{array}$ & $\begin{array}{l}U_{\mathrm{c}}=\alpha \times\left(\frac{y}{h_{\mathrm{c}}}\right)^{\beta} \times \sqrt{2 g\left(\frac{\rho_{\mathrm{c}}-\rho_{\mathrm{w}}}{\rho_{\mathrm{w}}}\right) h_{\mathrm{c}}} \\
\text { Being, } \\
\alpha, \beta: \text { empirical parameters for } \\
\quad \text { each vehicle } \\
y_{1} h_{\mathrm{c}}: \text { water depth and } \\
\quad \text { vehicle height } \\
\rho_{\mathrm{c}}, \rho_{\mathrm{w}}: \text { vehicle and water } \\
\quad \text { density }\end{array}$ & $\begin{array}{l}U_{\mathrm{c}}=\alpha \times\left(\frac{y}{h_{\mathrm{c}}}\right)^{\beta} \times \sqrt{2 g I_{\mathrm{c}}\left(\frac{\rho_{\mathrm{c}}}{\rho_{\mathrm{w}}} \frac{h_{\mathrm{c}}}{y}-\frac{h_{\mathrm{c}} \rho_{\mathrm{c}}}{h_{\mathrm{b}} \rho_{\mathrm{w}}}\right)} \\
\text { Being, } \\
\alpha, \beta: \text { empirical parameters for } \\
\quad \text { each vehicle } \\
y_{1} h_{\mathrm{c}}: \text { water depth and vehicle } \\
\quad \text { height } \\
\rho_{\mathrm{c},} \rho_{\mathrm{w}}: \text { vehicle and water density } \\
h_{\mathrm{b}}: \text { buoyancy depth } \\
l_{\mathrm{c}}: \text { vehicle length }\end{array}$ & $\begin{array}{l}\frac{F_{\mathrm{D}}}{\mu\left(M_{\mathrm{c}} g F_{\mathrm{b}}-F_{\mathrm{L}}\right)}=1 \\
\text { Being, } \\
F_{\mathrm{D}}: \text { water } \\
\text { drag force } \\
M_{\mathrm{c}}: \text { vehicle } \\
\text { weight } \\
F_{\mathrm{b}}: \text { buoyancy } \\
\quad \text { force } \\
F_{\mathrm{L}}: \text { lift force }\end{array}$ & $\begin{array}{l}\text { Parallel } \\
U_{\mathrm{c}}=\alpha \times\left(\frac{y}{h_{\mathrm{c}}}\right)^{\beta} \times \sqrt{2 g I_{\mathrm{c}}\left(\frac{\rho_{\mathrm{c}}}{\rho_{\mathrm{w}}} \frac{h_{\mathrm{c}}}{y}-\frac{h_{\mathrm{c}} \rho_{\mathrm{c}}}{h_{\mathrm{b}} \rho_{\mathrm{w}}}\right)} \\
\text { Perpendicular } \\
U_{\mathrm{c}}=\alpha \times\left(\frac{y}{h_{\mathrm{c}}}\right)^{\beta} \times \sqrt{2 g b_{\mathrm{c}}\left(\frac{\rho_{\mathrm{c}}}{\rho_{\mathrm{w}}} \frac{h_{\mathrm{c}}}{y}-\frac{h_{\mathrm{c}} \rho_{\mathrm{c}}}{h_{\mathrm{b}} \rho_{\mathrm{w}}}\right)} \\
\text { Being, } \\
\alpha, \beta \text { : empirical parameters for } \\
\text { each vehicle } \\
y, h_{\mathrm{c}}: \text { water depth and vehicle } \\
\text { height } \\
\rho_{\mathrm{c}} \rho_{\mathrm{w}}: \text { vehicle and water density } \\
h_{\mathrm{b}}: \text { buoyancy depth } \\
I_{\mathrm{c}}, b_{\mathrm{c}}: \text { vehicle length and width }\end{array}$ \\
\hline $\begin{array}{l}\text { Assumed coefficient } \\
\text { of friction }\end{array}$ & - & $\begin{array}{l}0.39 \text { (Transit); } \\
0.5 \text { (Focus) } \\
0.68 \text { (Volvo) }\end{array}$ & $\begin{array}{l}0.26 \text { (Sedan); } \\
0.42 \\
\quad \text { (Minivan) }\end{array}$ & $\begin{array}{l}0.25 \text { (parallel) } \\
0.75 \text { (perpendicular) }\end{array}$ \\
\hline
\end{tabular}

was not adequate since the weights of both scaled models (1:43 and 1:18) were not comparable; (2) the proposed threshold for prototypes vehicles is unsafe since the velocities are consistent only for vehicles much heavier than the real ones and (3) a buoyancy depth is not considered since the density of the scaled models is greater than the water density, therefore the vehicle does not become buoyant.

A development of a formula to predict the incipient velocity of flooded vehicles according to the mechanical condition of sliding equilibrium was carried out by Xia et al. (2010). This formula was validated based on the experimental results of Teo (2010) for the three tested small-scale (1:43) vehicles models. Being aware that the weight of the scaled models was not adjusted according to the Froude similarity, it was stated that: 'In the experiments, the density of the vehicles was significantly greater than in the prototype one. This meant that the model vehicles would be more submerged at the point of initiation of motion in the flume than in the prototype case'. Therefore, in order to fix this, a relative density term was included in the derived formula. Nevertheless, the buoyancy depth was not taken into account in this study, thus the representation of the derived formula reached depths even beyond vehicle heights.

A semi-empirical formula for critical motion conditions for partially submerged vehicles was derived by Shu et al. (2011), offering a new approach where the buoyancy depth was considered. Two main assumptions in this study were that four wheels were blocked at a time, and the vehicle 
was waterproof in order to consider a specific water depth that once exceeded, the vehicle becomes buoyant. As Keller and Mitsch (1993) proposed, drag coefficients of 1.15 for water depths below ground clearance and 1.10 for higher water depths were considered. It was stated that friction coefficient between tyres and ground was a key parameter in the determination of the critical incipient velocity, thus a range of potential values $(0.25-0.75)$ should be taken into account (Kurtus, 2005; Gerard, 2006). Experimental tests were carried out as well, in order to obtain two parameters of the derived formula $(\alpha, \beta)$ related to each tested model vehicle. The tests were based on three scaled vehicle models (1:18), Ford Focus, Ford Transit and Volvo XC90, and carried out in a horizontal flume of $1.2 \mathrm{~m}$ width in the laboratory of the Cardiff School of Engineering (UK). Moreover, tests to determine the friction coefficient for each model vehicle were carried out, obtaining values of 0.5 (Ford Focus), 0.39 (Ford Transit) and 0.68 (Volvo XC90).

In this case, similarity principles were rigorously followed (geometric, kinematic and dynamic), thus the selected density of the models were close to that of the corresponding prototype. Two vehicle orientation angles were considered: $0^{\circ}$ for vehicle front faced to the direction of the oncoming flow and $180^{\circ}$ for the rear front faced the oncoming flow direction. The results indicated no substantial difference in the conditions of incipient motion for both orientations and for all the tested vehicle models. Limits of stability (i.e. function of depth and velocity) for each prototype vehicle corresponding to the tested model vehicles were proposed; and validated on the basis of visual observations of real flooding events (2004 Boscastle flood, UK; and 2010 Var flood, France).

A variation of the Shu et al. (2011) formula was proposed by Xia et al. (2013) in order to include the effect of orientation, considering in addition $90^{\circ}$ flow exposition (i.e. relative to the vehicle length). This time experimental tests were conducted as well in order to obtain $\alpha$ and $\beta$ parameters of the new derived formula for each vehicle. The tests were based on two types of die-cast model vehicles at two model scales (1:14 and 1:24), Honda accord and Audi Q7. These experiments were conducted in a $1.2 \mathrm{~m}$ width flume of the Experimental Hall for Sediment and Flood Control Engineering, Wuhan University, China. After the tyre-ground friction coefficient of 0.75 was proposed for perpendicular orientation and 0.25 for parallel orientation for both vehicles. The validation of the limit function was undertaken with the smaller scale (1:24) model vehicles. The results showed no significant difference



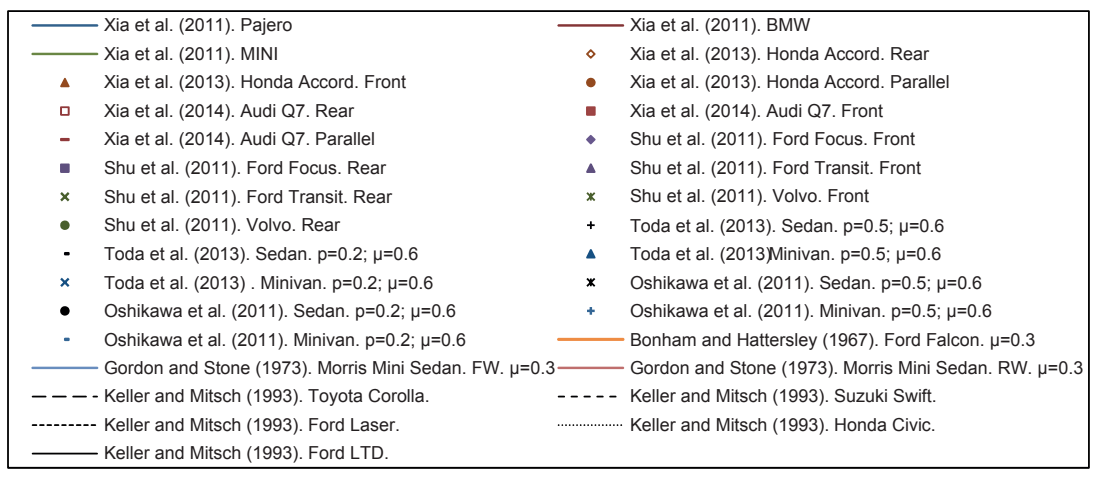

Figure 2 Representation of all the results from literature (instability points and limit functions) obtained in experimental and theoretical studies. 
in instability for the two orientations when the water depth reached to the buoyancy depth.

Other experimental studies were conducted by Toda et al. (2013) at Ujigawa Open Laboratory, Disaster Prevention Research Institute, Kyoto University, Japan. A new approach was adopted in this case, since the decrease of buoyancy by the water inside of the partially submerged vehicles was considered. The tests were carried out in a $1.0 \mathrm{~m}$ width mortar flume and two types of model vehicles were tested; a sedan-type and a minivantype with 1:10 and 1:18 scales, respectively. The similarity principles were followed and the weight of the model vehicle was adjusted by a small steel plate until the same density as the corresponding prototype was obtained. Contrary to previous works, the lift force was also considered in the force analysis. This force together with the buoyancy force decreases the gravitational force with the water depth increase. In order to consider the decrease of buoyancy by the water leaking into the vehicle, the relations between volume and water depth were obtained by measurements. The friction coefficients were measured for $0^{\circ}$ and $90^{\circ}$ model vehicle orientation, obtaining values of 0.26 and 0.57 , respectively, for sedan-type and values of 0.42 and 0.65 for minivan-type. Although, only tests setting the model vehicles in the same direction of flow were carried out in order to determine the instability of them.
On the other hand, the results of Oshikawa et al. (2011) were also represented which are corresponding to the same tests procedure but $90^{\circ}$ model vehicles orientation. The final conclusion is reduced to the statement that if the flow velocity is higher than $2 \mathrm{~m} / \mathrm{s}$ and the water depth is more than 0.5 , then vehicles are likely to being to move'.

A summary of all these experimental and theoretical studies is provided in Tables 1 and 2 and the representation of those in Figure 2.

\section{Recommendations or guidelines}

The main and up to date criterion regarding stability of vehicles is the one proposed in the Australian Rainfall and Runoff (AR\&R) guideline. In order to update the 1987 edition of $A R \& R$, this guideline was revised. This revision consists of 21 projects designed to fill knowledge gaps that have arisen since the 1987 edition. The 'revision project 10: Appropriate Safety Criteria for Vehicles' (Shand et al., 2011) presented a comprehensive comparison between previous guidelines and recommendations for vehicle stability and experimental and theoretical studies. Eight Australian guidelines or recommendations were considered in this review, covering Department of Public Works (1986);

Table 3 Summary of theoretical and analytical studies [adapted from Shand et al. (2011)]

\begin{tabular}{|c|c|c|c|c|}
\hline Guideline/Recommendation & Maximum depth $(y ; m)$ & $\begin{array}{l}\text { Maximum } \\
\text { velocity } \\
(\mathrm{v} ; \mathrm{m} / \mathrm{s})\end{array}$ & $\operatorname{Maximum}(\mathrm{v} \cdot \mathrm{y})\left(\mathrm{m}^{2} / \mathrm{s}\right)$ & Other \\
\hline $\begin{array}{l}\text { Department of Public Works } \\
\text { (1986), NSW }\end{array}$ & 0.3 & 2.0 & - & $\frac{-11 \cdot v+3.3}{y}<1$ \\
\hline $\begin{array}{l}\text { Australian Rainfall and } \\
\text { Runoff (Institution of } \\
\text { Engineers Australia, 1987) }\end{array}$ & - & - & $\begin{array}{c}0.6-0.7 \text { depending on } \\
\text { vehicle size }\end{array}$ & - \\
\hline $\begin{array}{l}\text { Melbourne Water (1996) } \\
\text { Land Development } \\
\text { Manual: Floodway Safety } \\
\text { Criteria }\end{array}$ & 0.6 & - & $\begin{array}{c}\leq 0.6 \text { for } y_{a v} \leq 0.1 \mathrm{~m} ; \leq 0.80 \\
\text { for } y_{a v}=0.2 \mathrm{~m} ; \leq 0.35 \text { for } \\
y_{a v} \geq 0.3 \mathrm{~m}\end{array}$ & - \\
\hline $\begin{array}{l}\text { Emergency Management } \\
\text { Australia (EMA) (1997) } \\
\text { Manual }\end{array}$ & - & - & - & $\begin{array}{c}\text { Maintain a bow wave and } \\
\text { outfit the vehicle in } \\
\text { depths }>750 \mathrm{~mm}\end{array}$ \\
\hline $\begin{array}{c}\text { Emergency Management } \\
\text { Australia (EMA) (1999) }\end{array}$ & $\begin{array}{c}0.3 \text { (small, light low cars); } 0.4 \\
\text { (larger, higher cars) }\end{array}$ & - & - & - \\
\hline Moore and Power (2002) & - & - & - & $\begin{array}{l}y \leq(0.4-0.0376 \mathrm{v}) \text { for } \\
{[\mathrm{v} \leq 1.81 \mathrm{~m} / \mathrm{s}] ;(\mathrm{v} \cdot \mathrm{y}) \leq 0.6} \\
\quad \text { for }[\mathrm{v}>1.81 \mathrm{~m} / \mathrm{s}]\end{array}$ \\
\hline $\begin{array}{l}\text { Floodplain Development } \\
\text { Manual (2005) }\end{array}$ & 0.3 & 2.0 & - & $\frac{-11 \cdot v+3.3}{y}<1$ \\
\hline Austroads (2008) & - & - & - & $y+\frac{\nu^{2}}{2 g} \leq 0.3$ \\
\hline $\begin{array}{l}\text { Australian Rainfall \& Runoff. } \\
\text { Project 10: appropriate } \\
\text { safety criteria for } \\
\text { vehicles (2011) }\end{array}$ & $\begin{array}{c}0.3 \text { (small passenger); } 0.4 \\
\text { (large passenger); } 0.5 \\
\text { (large 4WD) }\end{array}$ & 3.0 & $\begin{array}{c}\leq 0.3 \text { (small passenger) } ; \leq 0.45 \\
(\text { large passenger); } \leq 0.6 \\
\text { (large 4WD) }\end{array}$ & - \\
\hline
\end{tabular}



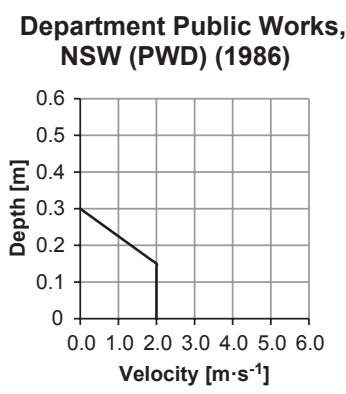

EMA (1999)

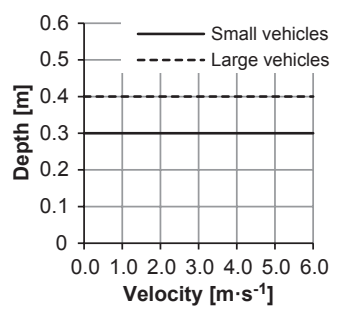

AR\&R (1987)

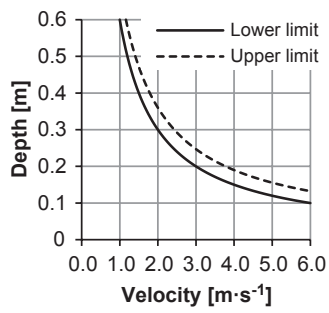

Moore and Power (2002)

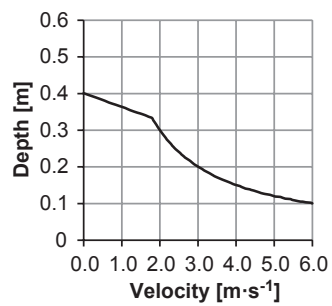

AR\&R (2011)

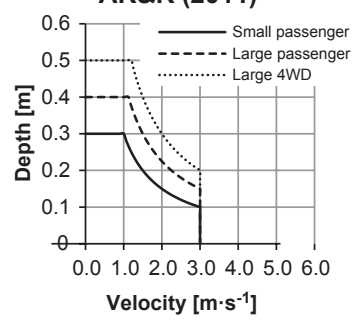

Melbourne Water Land

Development Manual (1996)



Austroads (2008)

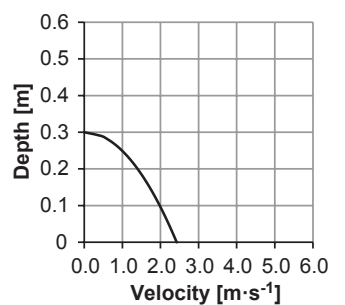

Figure 3 Representations of all the limit functions proposed in guidelines and recommendations in literature.

Institution of Engineers Australia (1987); Melbourne Water (1996); Emergency Management Australia and Queensland Government (2002); Moore and Power (2002); Department of Infraestructure Planning and Natural Resouces (New South Wales Goverment) (2005), and Austroads (2008). Others guidance documents from England, Japan, Canada and the United States reviewed within Keller and Mitsch (1993) suggest either non-quantitative limits or arbitrary limits with no theoretical background provided. A summary of the proposed criteria in each guideline is provided in Table 3 and the representation of those in Figure 3. There were only three experimental and theoretical studies assessed in the AR\&R project (Bonham and Hattersley, 1967; Gordon and Stone, 1973; Keller and Mitsch, 1993), being impossible the assessment of subsequent studies (Xia et al., 2010; Shu et al., 2011; Toda et al., 2013; Xia et al., 2013) which were published very close or after new AR\&R Guideline was. The final proposed draft stability criteria for stationary vehicles distinguish among three class of vehicles; small passenger, large passenger and large $4 \mathrm{WD}$.

For each one, a stability limit function [i.e. product velocity times water depth $(\mathrm{v} \cdot \mathrm{y})]$ is offered and defining a maximum velocity and a maximum water depth (buoyancy depth). The characteristics for each type of vehicle and the proposed limit functionarepresentedinTable4.

\section{AR\&R criterion verification}

A verification of the AR\&R criterion has been carried out herein, by comparing the proposed limits with the subsequent theoretical and experimental studies which were not considered to define these safety thresholds. This criterion remains valid according to the graph presented in Figure 4, where the results of subsequent studies are presented together with the three limit stability functions. Only two instability points are found below large passenger limit, corresponding to a sedan vehicle type of Toda et al. (2013) and Oshikawa et al. (2011) studies. No instability points corresponding to large $4 \mathrm{WD}$ are found below the limit for those. Therefore, the AR\&R criterion appears to be the best reference to date on the stability of these three types of vehicles. 
Table 4 Proposed AR\&R draft stability criteria for stationary vehicles (Shand et al. (2011)

\begin{tabular}{llllllll}
\hline $\begin{array}{l}\text { Class of } \\
\text { vehicle }\end{array}$ & $\begin{array}{l}\text { Length } \\
(\mathrm{m})\end{array}$ & $\begin{array}{l}\text { Kerb } \\
\text { weight }(\mathrm{kg})\end{array}$ & $\begin{array}{l}\text { Ground } \\
\text { clearance }(\mathrm{m})\end{array}$ & $\begin{array}{l}\text { Limiting still water } \\
\text { depth }(\mathrm{m})\end{array}$ & $\begin{array}{l}\text { Limiting high velocity } \\
\text { flow depth }(\mathrm{m})\end{array}$ & $\begin{array}{l}\text { Limiting } \\
\text { velocity }\end{array}$ & $\begin{array}{l}\text { Equation of } \\
\text { stability }\left(\mathrm{m}^{2} / \mathrm{s}\right)\end{array}$ \\
\hline $\begin{array}{l}\text { Small } \\
\text { passenger }\end{array}$ & $<4.3$ & $<1250$ & $<0.12$ & 0.3 & 0.10 & 3.0 & $(\mathrm{v} \cdot \mathrm{y}) \leq 0.30$ \\
$\begin{array}{c}\text { Large } \\
\text { passenger }\end{array}$ & $>4.3$ & $>1250$ & $>0.12$ & 0.4 & 0.15 & 3.0 & $(\mathrm{v} \cdot \mathrm{y}) \leq 0.45$ \\
$\begin{array}{l}\text { Large 4WD } \\
\text { P }\end{array}$ & $>2000$ & $>0.22$ & 0.5 & 0.20 & 3.0 & $(\mathrm{v} \cdot \mathrm{y}) \leq 0.60$ \\
\hline
\end{tabular}

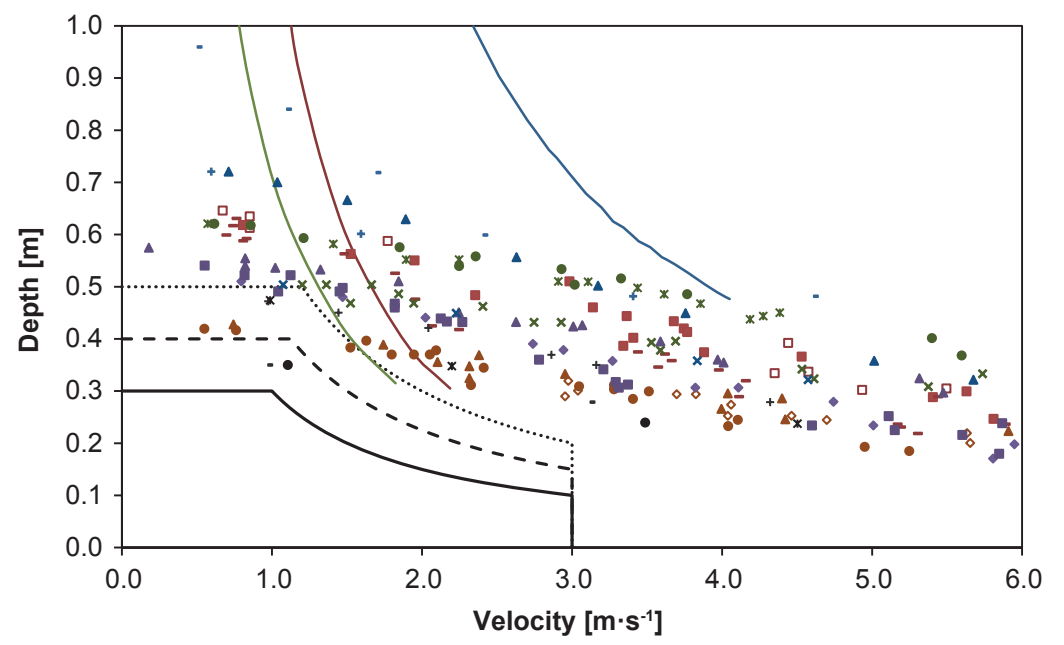

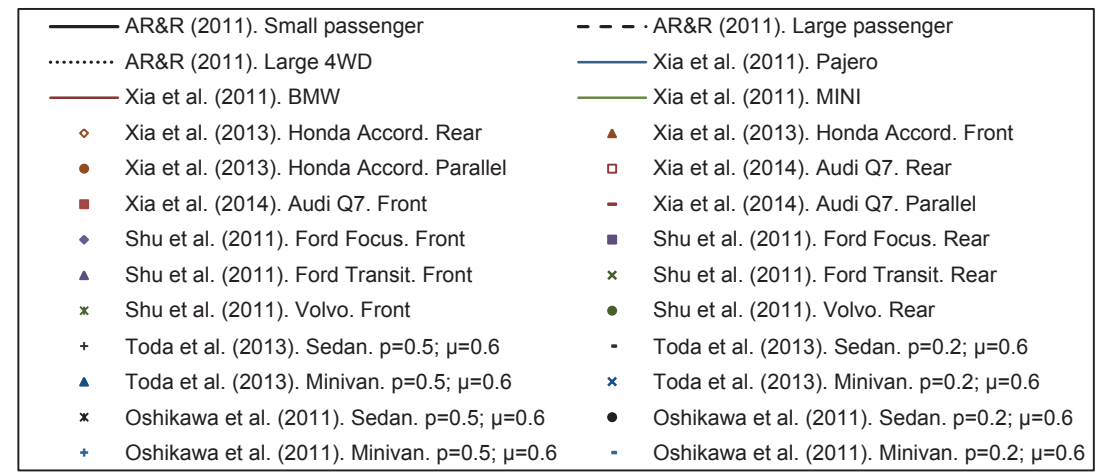

Figure 4 Verification of the AR\&R criterion by comparison with results of subsequent theoretical and experimental studies.

\section{Conclusions}

Previous experimental studies regarding stability of vehicles exposed to flooding have been reviewed and it appeared that no study included a test with more than two or three scale model vehicles; therefore it was not possible to develop a general methodology for any real vehicle. The AR\&R criterion was the best reference up to now to guarantee the stability of vehicles according to three types of vehicles, which has been updated and validated herein with the results of subsequent studies. Nevertheless, the proposed criterion is not flexible enough to consider any vehicle with different characteristics.
In any case, it is necessary to carry out a comprehensive experimental campaign by testing a great sample of scale vehicles in order to obtain a general method to define the stable area in the flow depth-velocity domain for any vehicle. This experimental campaign should consider a representative sample of scale models. The analysis of the most influential parameters of vehicles (ground clearance, weight, shape, etc.) regarding their stability in floods would let to us to derive a proper coefficient to sort vehicles according their stability. Therefore, a representative sample of scale models would include different types of vehicles ranged from the lowest to the highest stability. All scale models should be tested for flow conditions (i.e. sub and 
supercritical flows) according to the depth-velocity domain analysed by the previous authors. Frictional and buoyancy tests must be involved in the experimental campaign in order to offer the most accurate results. Frictional tests will offer adequate frictional coefficients to ensure that those are realistic according prototype real values. Buoyancy tests will offer buoyancy depths for each tested vehicle where no flow velocity is considered. No longer be said that in order to validate the results real prototype vehicles would be able to be tested in large-scale flume.

The last objective would be to provide a tool that decision-makers in the field of urban flood risk management can employ to obtain for any design vehicle its corresponding stability threshold.

\section{Acknowledgements}

The corresponding author wishes to thank the Spanish Ministry of Economy and Competitiveness for the personal financial collaboration in relation to the Scholarship with reference: BES-2012-051781. This work is framed on the research project Criterios de riesgo a aplicar en el diseño de sistemas de captación ante inundaciones en medio urbano. This research project is funded by the Spanish Ministry of Economy and Competitiveness with code CGL2011-26958.

\section{References}

Abt S.R., Wittler R.J., Taylor A. \& Love D.J. Human stability in a high flood hazard zone. J Am Water Resour Assoc 1989, 25, 881-890.

Austroads Guide to road design, part 5: drainage design. AustRoads Inc, Australia, 2008, 210.

Bonham A.J. \& Hattersley R.T. Low Level Causeways. WRL Report No. 100. University of New South Wales. Australia, Sydney, 1967, 30.

Concha R. \& Gómez M. Una aproximación a la modelización del Drenaje Dual Urbano mediante EPA SWMM 5.0. Jornadas Ing. del Agua 2009 (JIA 2009). Barcelona, Spain, 2009, 1-10.

Cox R.J., Shand T.D. \& Blacka M.J. Australian Rainfall and Runoff (AR\&R). Revision Project 10: Appropriate Safety Criteria For People. NSW: Department of Infraestructures Planning and Natural Resources, 2010.

Department of Infraestructure Planning and Natural Resouces (New South Wales Goverment) Floodplain development manual: the management of flood liable land, Vol. 31. Sydney, NSW: Department of Public Works, 2005.

Department of Public Works Floodplain development manual. Sydney, NSW: Department of Public Works, 1986, 72.

Djordjevic S., Prodnovic D. \& Maksimovic C. An approach to simulation of dual drainage. Water Sci Technol 1999, 39, 95-103. doi: 10.1016/S0273-1223(99)00221-8.
Emergency Management Australia (EMA) Four-wheel-drive vehicle operation. Australian Emergency Manuals Series, Part IV, Manual 8: Skills for Emergency Services Personnel, Canberra, NSW: Emergency Management Australia, 1997, 76.

Emergency Management Australia (EMA) Managing the floodplain. Australian Emergency Management Series, Part 3, Volume 3, Guide 3, Canberra, NSW: Emergency Management Australia, 1999, 107.

Emergency Management Australia and Queensland Government Disaster loss assessment guidelines (Guide 11). Part IIIEmergency Management Practice. Volume 3-Guidelines, Canberra, NSW: Emergency Management Australia, 2002, 101.

Gerard M. Tire-road friction estimation using slip-based observers. Master Thesis. Department of Automatic Control, Lund University, Sweden, 2006.

Gordon A.D. \& Stone P.B. Car stability on road causeways. WRL Technical Report No. 73/12. University of New South Wales. Australia, Sydney, 1973.

Institution of Engineers Australia. Australian Rainfall and Runoff, Vol. 1\&2, Pilgrim, D. Australia, 1987.

Keller R.J. \& Mitsch B. Safety aspects of the design of roadways as floodways. Research Report No. 69. Urban Water Research Association of Australia, 1993, 41.

Kurtus R. Coefficient of Friction Values for Clean Surfaces, $2005 . \quad$ www.school-for-champions.com/science/friction coefficient.htm [accessed 5 November 2014].

Martínez-Gomariz E., Gómez M. \& Russo B. Experimental study of the stability of pedestrians exposed to urban pluvial flooding. Nat Hazards 2016, 82, 20. doi: 10.1007/s11069-016-2242-z.

Melbourne Water. Melbourne water land development manual, Appendix A: floodway safety criteria. Melbourne Water Technical Working Group: R Sutherland, T Jones, N Craigie. Melbourne, Australia, 1996.

Moore K. \& Power R. Safe buffer distances for offstream earth dams. Aust J Water Resour 2002, 6, (1), 1-15.

Nanía L.S., León A.S. \& García M.H. Hydrologic-hydraulic model for simulating dual drainage and flooding in urban areas: application to a catchment in the metropolitan area of Chicago. J Hydrol Eng 2015, 20, 04014071. doi: 10.1061/ (ASCE)HE.1943-5584.0001080.

Nasello C. \& Tucciarelli T. Dual multilevel urban drainage model. J Hydraul Eng 2005, 131, 748-754. doi: 10.1061/ (ASCE)0733-9429(2005)131:9(748).

Oshikawa H., Oshima T. \& Komatsu T. Study on the Risk for Vehicular Traffic in a Flood Situation (in Japanese). Adv River Eng 2011, 17, 461-466.

Russo B., Gómez M. \& Macchione F. Pedestrian hazard criteria for flooded urban areas. Nat Hazards 2013a, 69, 251-265. doi: 10.1007/s11069-013-0702-2.

Russo B., Velasco M. \& Suñer D. Flood hazard assessment considering climate change impacts-Application to Barcelona case study using a $1 \mathrm{D} / 2 \mathrm{D}$ detailed coupled model. International Conference on Flood Resilience: Experiences in Asia and Europe. Exeter, UK, 2013b, 10. 
Sanyal J. \& Lu X.X. GIS-based flood hazard mapping at different administrative scales: a case study in Gangetic West Bengal, India. Singap J Trop Geogr 2006, 27, 207-220. doi: 10.1111/ j.1467-9493.2006.00254.x.

Schmitt T.G., Thomas M. \& Ettrich N. Analysis and modeling of flooding in urban drainage systems. J Hydrol 2004, 299, 300-311. doi: 10.1016/j.jhydrol.2004.08.012.

Shand T.D., Cox R.J., Blacka M.J. \& Smith G.P. Australian rainfall and runoff (AR\&R). Revision project 10: appropriate safety criteria for vehicles. Report Number: P10/S2/020, 2011.

Shu C., Xia J., Falconer R.A. \& Lin B. Incipient velocity for partially submerged vehicles in floodwaters. J Hydraul Res 2011, 49, 709-717. doi: 10.1080/00221686.2011.616318.

Teo F.Y. Study of the hydrodynamic processes of rivers and floodplains with obstructions. PhD Thesis. Cardiff University, 2010.

Teo F.Y., Xia J., Falconer R.A. \& Lin B. Experimental studies on the interaction between vehicles and floodplain flows. Int J River Basin Manag 2012, 10, 149-160. doi: 10.1080/15715124.2012.674040.

Teo F.Y., Liew Y.S., Falconer R.A. \& Lin B. Estimation of flood hazard risk relating to vehicles. 35th IAHR World Congress, Chengdu, China, 2013, 8.
Toda K., Ishigaki T. \& Ozaki T. Experiments study on floating car in flooding. International Conference on Flood Resilience: Experiences in Asia and Europe, Exeter, UK, 2013, 6.

Van Drie R., Simon M. \& Schymitzek I. HAZARD: is there a better definition? \& Impact of Not accounting for buildings! IPWEA Annual Conference, New South Wales (NSW), Australia, 2013, 13.

Xia J., Teo F.Y., Lin B. \& Falconer R.A. Formula of incipient velocity for flooded vehicles. Nat Hazards 2010, 58, 1-14. doi: 10.1007/s11069-010-9639-x.

Xia J., Falconer R.A., Xiao X. \& Wang Y. Criterion of vehicle stability in floodwaters based on theoretical and experimental studies. Nat Hazards 2013, 70, 1619-1630. doi: 10.1007/ s11069-013-0889-2.

Xia J., Falconer R.A., Wang Y. \& Xiao X. New criterion for the stability of a human body in floodwaters. J Hydraul Res 2014, 52, 93-104. doi: 10.1080/00221686.2013.875073.

Xia J., Chen Q., Falconer R.A., Deng S. \& Guo P. Stability criterion for people in floods for various slopes. Proc ICE Water Manag 2016, 169, 180-189. doi: 10.1680/wama.14.00110. 